\title{
The Strategy of Small and Medium-sized Enterprises to Build Health Information Ecosystem
}

\author{
Li Rui ${ }^{1, *}$ \\ 1JiLin Engineering Normal University, \\ Changchun, Jilin, China \\ e-mail: arnold0110@sina.com \\ * Corresponding Author
}

\begin{abstract}
On the basis of the information ecology theory research, Combined with the problems existing in the enterprise information ecosystem, In-depth analysis of the problem such as optimal allocation of enterprise information ecosystem 、 Enterprise information index system of ecosystem health index design 、enterprise information ecosystem health evaluation method, Put forward the concrete strategy to build health information ecosyste.
\end{abstract}

Keywords-information ecosystem; Health information ecosystem; Ecosystem management; The information of enterprise

\section{INTRODUCTION}

The importance of enterprise information ecosystem is growing in the enterprise management system, This is not only reflected in the enterprise information ecosystem is the core of the whole enterprise operation, and is one of the important determinants of enterprise core competitiveness. Many large enterprises have obtained the success of the informatization construction stage, many small and medium-sized enterprises also gradually began to undertake information construction, but for small and medium-sized enterprises information construction and application level is still low. Therefore, this article try to use information ecology principle to guide the informatization construction of small and medium-sized enterprises, construction of small and medium-sized enterprise health information ecosystem, realize the sustainable development of informatization construction.

\section{OVERVIEW OF ENTERPRISE INFORMATION ECOSYSTEM}

\section{A. The connotation of enterprise information ecosystem}

Information ecosystem is to point to by the people in a specific environment, practice, technology and value of a system. Information ecosystem is a network of people, technology, network and knowledge network three network integration, enterprise information ecosystem constitute by the enterprise information system and its internal and external environment, including people, technology, information and practice, the composition is of matter, information and energy exchange, is the enterprise of each department information and mutual

\author{
Zhang $\mathrm{Na}$ \\ College of Art and Design \\ Shenyang Jianzhu University \\ Shenyang, China
}

influence between departments and interrelated organic whole.

\section{B. The constituent elements of enterprise information ecosystem}

information refers to all the needed information and to participate in the activities of an individual or a social organization, in fact each and every social organization is the information. Information is the main body of enterprise information ecosystem, he is always the most important in the management or decision making, the role of carrier of information are many, but in the end is a thinking person to tidy, digestion, to master and apply, it is irreplaceable in the information management, only by people to apply the information to make the information to create value and profits, to adapt to market competition, the enterprise information ecosystem play an irreplaceable important role.

Information ecological environment is the enterprise growth, propagation and consumption of the relationship between the macroscopic form, has the characteristics of balance coordination, it constitutes the enterprises to carry out various activities of social environment. The situation of the information environment of enterprise information has a decisive role in the sustainable development of ecological system, has a great influence on the subject and object of system.

\section{THE CURRENT SITUATION OF SMALL AND MEDIUM- SIZED ENTERPRISE INFORMATION ECOSYSTEM}

\section{A.The small and medium-sized enterprise informatization development imbalance}

Look from the enterprise type, mainly in small and medium-sized enterprise informatization development imbalances, foreign investment enterprises, exportoriented enterprises, science and technology enterprises, high correlation with large enterprises of small and medium-sized enterprises by the rapid development of information technology, and competitiveness of the weak, poor efficiency of enterprises and development of township enterprise information more slowly.

From the regional distribution, mainly in small and medium-sized enterprise informatization development imbalances, economic development level and the high degree of marketization of regional informatization development level is higher. Compared with the eastern, 
western China enterprise informationization is still in the stage of underdeveloped.

B.Small and medium-sized enterprise informatization imbalance

Small and medium-sized enterprise information technology has made some achievements in the research, especially in the research on the establishment of the system has reached a certain depth, but the related technology into products, related products into industrial level is low, did not play its due effect. Conversion technology, the degree of marketization of enterprises is low or smaller or less relevant policies to support, not form the scale of the overall effect.

C.Small and medium-sized enterprise informationization implementation of imbalance

As the growth of the small and medium-sized enterprise business, enterprise applications such as ERP, PDM system has been deployed individually, different system or module is provided by different vendors respectively, isolated building and implementing, causing most of the "information island" of the enterprise application systems. Monomer, departmental application, enterprise application integration. Application system in different forms of data are stored in different database, and various business systems usually respectively by the different functions of the management and maintenance, distribution in different areas, combined with the network and information security protection measures, make the system function between cross each other, have repeated information and data, but each other is hard to smooth information exchange and sharing, forming a "information island", thus appeared the phenomenon such as data updates are not synchronized, provides some inconsistent information to the customer.

\section{D.Small and medium-sized enterprise informationization management ideas and talent don't balance}

Informatization is a revolution of management and corporate culture, business leaders and many small and medium enterprises not heavy demand, in order to informatization and informatization, don't realize the effect of informatization. Informationization and enterprise business process actually together, can we truly reflect all of its effectiveness. Many managers even believe that informationization is the copy of the original business process, is a software company's business.

Management system is not sound, management mechanism is not stable, unscientific management decision, business processes, informality leads to the backward management thoughts and cannot adapt the advanced information technology, reduce the economic benefits brought by the information. Therefore, the imbalance of management concept and information technology is the main factor affecting the small and medium-sized enterprise information ecological equilibrium.

Lack of informatization talents, from the statistic survey, our country small and medium-sized enterprise information technology personnel proportion of the total number of employees is very low, especially know both technology and understand business processes and business management backbone talents more scarce, and erosion is serious, this is largely restricted the quality and speed of the enterprise information construction. At the same time because of various subjective and objective factors, regards the light application equipment, heavy light technology talents cultivation, the internal organization of information system construction of light the phenomenon of information resources sharing, continuously updated and evolve independently ability is insufficient, the further hindered the small and mediumsized enterprise informationization and sustainable and healthy development.

\section{THE CONSTRUCTION OF HEALTH INFORMATION ECOSYSTEM STRATEGY}

\section{A. Choose suitable for the construction of enterprise information ecosystem strategy}

Enterprise information ecosystem growth strategic choice. After their initial resource reserves and environmental construction, information ecosystem into the growth period, growth period in the system's main strategic positioning in optimizing the allocation of resources, maintain system and matching between businesses, improve system growth momentum. System as well as the overall strategic resources of configurability, take various effective method and approach of marketization, set up a more standardized management system, enlarge the range of information technology, to realize the recycling of resources factors.

Enterprise information ecosystem optimization phase of strategic choice. Into the optimization stage, information ecosystem management level is higher, stable internal structure, management performance is good, mature technology conditions, perfect the policy system. Enterprise information ecosystem development strategic choice. As companies in survival, development and competition situation, information system as well as the increasing expansion of the scale, external information environment has been changing. At this point, the system is faced with the overall development process, should be carried out strategic resources structure adjustment, on each element in the system, structure adjustment and optimization, realize the development of system transition and internal demands and the environment, continuous monitoring, control, information ecosystem and the matching of enterprise development.

\section{B. Build an appropriate construction of enterprise information ecosystem environment}

Enterprise information ecosystem once finish it will be difficult to make big changes, thus to build a good ecological environment must be in overall planning, information under the premise of reasonable layout, have a goal, a hierarchical propulsion. Information environment of good or not is directly related to whether to build a benign health information ecological system, the optimization of information environment is critical to build harmonious information ecology. In the process of the construction of enterprise information ecosystem, the 
need to establish a suitable for the development of the enterprise information environment, cultivate good for enterprise requirements and the development of the information culture and ethics, make appropriate information policy, perfect the construction of information infrastructure, to create an environment factor information ecological environment coordinate with each other.

From a macro perspective, the enterprise information ecosystem industry information ecosystem in the internal system of information environment need to be established and the relative external information ecosystem environment benign.

\section{Pay attention to enterprise information ecosystem construction of key elements}

Information is the main body of enterprise information ecosystem, people is highly motivated in the system, the elements of information acquisition, development, processing and utilization of information people are needed to realize functions, such as the enterprise information ecosystem, the information people's quality directly determine the efficiency and the overall function of information ecosystem. Therefore, in the enterprise information ecosystem build, development and evolution process, the need to actively organizing training, education, improve the quality of the information people, guarantee the information timely, efficient utilization and benign development of the system. Information behavior on the individual performance for quality. From the point of view of system and the enterprise, the performance for the enterprise information culture, it reflects in the way of working, learning style, lifestyle and other social fields. The construction of enterprise information culture can develop to the way to the thinking mode of employee information and news, deciding the success or failure of the enterprise information construction, at the same time can significantly reduce the cost of enterprise information and cycle, improve the enterprise investment yields, and enterprise information form the benign mechanism of mutual promotion.

With the development of the enterprise, information structure also need to adapt to development. In enterprise information ecosystem, for example, the scale of the enterprise, the greater the corresponding demand will be large amount of information, the higher requirements for the quality of information people can also, policy makers and managers of enterprise organization structure, business executives is corresponding to different quality of information, decision-making information people use information from a more macro strategic point of view, and executive management mainly from the business point of view, the use of information information between people and information organization structure match each other.

D. Strengthen the enterprise information resources development and ecological system to establish information sharing

Small and medium-sized enterprise is in primary stage of construction of information ecosystem, due to incomplete information foundation facilities, the network is not sound, repeated investment, redundant construction in some project problem is widespread, and it also caused the waste of information resources, is not conducive to the healthy development of the enterprise information ecosystem. To solve this problem is we need to reasonable development and utilization of information resources, information resources in order to achieve the maximum utility. The whole enterprise information ecosystem, the information should be Shared, different subsystems can be through the reasonable channel and using system information resources. Sharing of the information can effectively reduce the redundant information and garbage information, improve the efficiency of the use of information, in the process of enterprise development, the amount and type information will be more and more big, the rational allocation of information resources, realizing information resources sharing can meet the needs of the masses of users to a great extent, reduce the user requirements and the actual number asymmetry phenomenon, reduce waste. Therefore, the use of information technology, infrastructure and other means and methods, development and utilization of information resources, relying on in all the information of power system, the correlation between each subsystem, perfecting the information transmission channel, establish perfect information sharing mechanism, guarantee the information resources "sharing ", makes any time and place, within the system information people can get what they need, the maximum to meet the demand of information resources.

\section{E. Coordinate the relationship between the elements in the construction of enterprise information ecosystem}

Information ecological system and ecological system, ecological system diversity, complexity and dynamic, in the process of enterprise information ecosystem construction, to coordinate the relationship between the various elements, to achieve the benign interaction between the various elements, made within the specific information system by the interaction between information, information and environment constitute a balanced state of motion, is the basic mechanism of information for enterprise development goals, and their survival needs, on own initiative to adapt to, the use of objective information environment, information in the whole system to realize the benign consumption cycle, ultimately drive system in the flow of information and energy as well as the development of the whole system evolution, at the same time, the information people can use their knowledge reserves and initiative to improve the information environment, through the interaction between the several elements of ecological cycle, information resources to use, information on human survival and development, enterprise information environment update and progress, the development of enterprise information ecosystem benign evolution. 


\section{F. Perfect the enterprise strategy of the construction of information ecosystem}

Information ecological balance refers to the ecological system of mutual coordination between each component is complementary, improve overall system structure and function of good a relatively stable state, in such a state of equilibrium, the system information of reasonable matching, information such as the amount and type of ecological environment factor and mutual coordination, information and information highly adapt to ecological environment, the information flow of the whole system is efficient. Enterprise information ecosystem balance is mainly two aspects:

First, the information ecological system structure optimization. In ecological system of information between various components of mutual matching and mutual coordination, adapt to each other and complement each other, in particular, in the system information one species is well-found, the different roles of information people have to perform his duties required quality, quantity and proportion, information people's ecological niche is reasonable, and can with the organization and coordination, and evolve with the organization's development.

Second, the information system is relatively stable and has good function. Overall information ecosystem over a longer period of time remained relatively stable, information input and output, enterprise information types, the proportion of relatively stable, system operation is good, the channels of information, information can realize to the letter

As enterprise information ecosystem, need to evolve to adapt to the environment request, although in the real information in the process of building ecological system design can't meet the predict of changes to the environment, but existing information ecological system should have certain elasticity, to adapt to the requirements of the external environment, alleviate the system the impact of the external environment mutation, maintain the relative stability of the system.

From the point of view of the enterprise, because of the limitation of resources, conditions, enterprise information ecosystem cannot fully meet the requirements of enterprise information, information accuracy, therefore, establishing benign with external information ecosystem and environment of information ecosystem has a good promoting effect to the enterprise information utilization. The whole process of enterprise information ecosystem for all enterprise life provides all kinds of information requirements, release and fusion, the use of the environment and platform. Companies from

Information is the main body of enterprise information ecosystem, are elements of a system with initiative, is the "keystone species" in information ecosystem, information acquisition, development, processing and utilization of information people are needed to realize functions, such as the enterprise information ecosystem, the information of quality directly decides the information efficiency and the overall function of information ecosystem. Therefore, in the enterprise information ecosystem build, development and evolution process, the need to actively organizing training, education, improve the quality of the information people, guarantee the information timely, efficient utilization and benign development of the system. Information behavior refers to how individuals think and process information. This includes the query information, using information, modify information, share information, storage information, and even ignore it.

To improve the information and the degree of match information organization structure, only by improving the information technology education, reduce the use of the language barrier and retrieval technologies in the process of obstacle, to cultivate information acquisition, information screening and carrying capacity, clear information of different levels of information processing, and utilization of requirements, to make the information and the enterprise to achieve better coordination, in order to better safeguard system of the ecological environment, maintain the balance and stability of the system.

\section{CONCLUSION}

With the development of economy and the enterprise the competition, the enterprise information construction will gradually become an important factor of enterprise strategic advantage in the competition, through the construction of enterprise information ecosystem can provide extensive information sharing platform for enterprise employees, improve the efficiency of the use of information, achieve the efficient allocation of resources enterprise, make the enterprise in a competitive market economy environment, promote the realization of the enterprise value maximization.

\section{REFERENCES}

[1] Chen yuang,The ultimate goal of the enterprise information: build health [J]. Intelligence magazine , 2007, (6) : 108-110.

[2] BrueeW.Managingtheinformationeeology:Aeollaborative approaeh To information teechnologymanagement.QualityProgress, 1997,579

[3] Erik Assadourian. Global Economic Growth Continues at Expense of Ecological

[4] SA.L.Eryomin. Ecology and Society' s Development[C]. 1st International Conference, Saint-Peter burg, Center of IAESVS, 1995 : 238-239.

[5] Grant Havers. The right-wing postmodernism of Marshal Mc Luhan Media [J]. Culture \& Society, 2003(7) : 510-513.

[6] Bonnie A. Nardi, Vichi L. O. Information Ecologies: Using Technology with heart [M]. The MIT Press, 1999.

[7] Gerard Prendergast, Pierre Berthon. Insights from Ecology : An Ecotone Perspective of Marketing [J]. European Management Journal, 2000, 18(2) : 223-232.

[8] Jacquelyn Marie Erdman. Library web ecology: what you need to know as web design coordinator[M]. Oxford: Chando, 2009.

[9] Saloner G A, Podolny J. Strategic management[M]. New York: John Wiley\&Son, Inc, 2001.

[10] Danah boyd. Social Media Changing our Information Ecology[J]. ITI Bloggers, 2008 (22): 112-130 